\title{
NICE shared decision making guidelines and mental health: challenges for research, practice and implementation - CORRIGENDUM
}

Yaara Zisman-Ilani, Marta Chmielowska, Lisa B. Dixon and Shulamit Ramon

\section{Keywords}

Patients; shared decision making; serious mental illness; NICE; policy

\section{Copyright and usage}

(C) The Author(s), 2021. Published by Cambridge University Press on behalf of the Royal College of Psychiatrists. This is an Open Access article, distributed under the terms of the Creative commons Attribution licence (http://creativecommons.org/licenses/by/4.0/), which permits unrestricted re-use, distribution, and reproduction in any medium, provided the original work is properly cited.

https://doi.org/10.1192/bjo.2021.987, Published online by Cambridge University Press, 2 September 2021.

The author and Publisher would like to correct the following references:
Reference 9 should be listed as:

Zisman-Ilani, Y, Lysaker, P., Hasson-Ohayon, I. Shared Risk Taking: Shared Decision Making in Serious Mental Illness. Psychiatr Serv 2021; 72(4): 461-463.

The Publisher apologises for this error.

\section{Reference}

1 Zisman-llani Y, Chmielowska M, Dixon L, Ramon S. NICE shared decision making guidelines and mental health: Challenges for research, practice and implementation. BJPsych Open 2021; 7(5): e154. doi:10.1192/bjo.2021.987

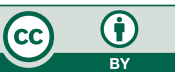

